\title{
Upgrading of IOT Big Data Governance Scheme in Microenterprise Governance
}

\author{
Dewen Liu $\mathbb{D}^{1}$ and Jian Wang $\mathbb{D}^{2}$ \\ ${ }^{1}$ School of Management, Nanjing University of Posts and Telecommunications, Nanjing, 210003 Jiangsu, China \\ ${ }^{2}$ College of Business, Shanghai University of Finance and Economics, Shanghai 200433, China \\ Correspondence should be addressed to Jian Wang; cob.wangjian@163.sufe.edu.cn
}

Received 20 January 2022; Revised 16 February 2022; Accepted 17 February 2022; Published 27 February 2022

Academic Editor: Kalidoss Rajakani

\begin{abstract}
Copyright (c) 2022 Dewen Liu and Jian Wang. This is an open access article distributed under the Creative Commons Attribution License, which permits unrestricted use, distribution, and reproduction in any medium, provided the original work is properly cited.
\end{abstract}

\begin{abstract}
The accelerated development of the tertiary industry is the inevitable result of productivity improvement and social progress. Vigorously developing the tertiary industry is conducive to enhancing the stamina of agricultural production, promoting the socialization and professionalization of industrial and agricultural production, optimizing the production structure, promoting the full development of the market, and alleviating employment pressure so as to promote the sustained, rapid, and healthy development of the entire economy. Microenterprises are one of the carriers for the development of the tertiary industry. Microenterprises can effectively alleviate the country's increasingly serious employment problems. However, with the saturated operation of microenterprises, the competition of microenterprises is becoming more and more intense. Small- and mediumsized enterprises are under the pressure of competition in terms of manpower, location, consumption level, and supply of goods. At the same time, small- and medium-sized enterprises are also facing problems such as high operating pressure, rising costs, financing difficulties, and heavy taxes and fees. In this environment, if small enterprises want to maintain long-term development, they must adapt to new forms and take active measures. Small- and medium-sized enterprises must use flexible and diverse forms of employment, actively adjust the industrial structure, vigorously develop the tertiary industry, and absorb more employed labor. The purpose of this paper is to study the use of IOT big data to optimize and upgrade the governance scheme of microenterprises. The purpose is to improve the governance effect of microenterprises and promote the development of microenterprises. This paper proposes optimal governance based on the collaborative algorithm and Pareto algorithm and conducts governance evaluation in multiple aspects of microenterprises, respectively. After obtaining the relationship with profit maximization, this paper finally analyzes and summarizes, obtains two optimal schemes, and evaluates and compares these two schemes with the traditional scheme. The results show that the profit maximization degree of the two schemes can reach $92 \%$. Compared with the traditional scheme, the maximum profit of small enterprises after the implementation of governance has increased by about $30 \%$.
\end{abstract}

\section{Introduction}

With the rapid development of the Internet of Things, more and more small bosses are starting small businesses. Microenterprises not only make a significant contribution to the economic development of the country but also provide numerous employment opportunities for people who need work. The development of microenterprises has injected new vitality into the country's economic development, and its development depends on the growth of microentrepre- neurs, and the success of microentrepreneurs requires corresponding support and assistance from the government and society. Among them, it is particularly important to let microentrepreneurs master the knowledge and skills to effectively start a business.

Since most of the entrepreneurs of small- and mediumsized enterprises in China are starting their own businesses for the first time, they have almost no experience with their partners. Entrepreneurs do not have the tradition of contract culture in culture but focus on face and human feelings. 
Contract culture refers to the sum of the spiritual and institutional elements of contracts. Contract culture is also a reflection of economic relations, legal relations, and will relations under the conditions of a market economy. It is a spiritual culture that permeates the entire process of market economy development. During the start-up period, everyone worked hard to build the enterprise first, ignoring the laws and regulations that regulate the corporate governance structure. When microenterprises encounter difficult entrepreneurial bottlenecks, contradictions become increasingly apparent. Enterprise contradictions mainly appear in the contradiction between environmental requirements and internal requirements of the organization, the contradiction between organizational goals and personal goals, and the contradictions between science, rationality, and human nature. In response to these contradictions, entrepreneurs and their partners insist on their own opinions, shirk their responsibilities, and even blame each other, and in the end, the companies they have worked so hard to create may fail due to mutual disputes. Therefore, the governance of microenterprises should be carried out at the beginning of the business, and corporate governance should be carried out from the aspects of standardizing the structure of the enterprise, improving the governance system, and regulating the operation of the enterprise in the form of contracts.

However, compared with foreign microenterprise governance research, domestic research is relatively lagging behind, and the research depth and breadth are not enough, and the current research has not yet formed a relatively complete system. For an enterprise, whether it has a sound governance system determines the length of the survival time of a small enterprise. In recent years, IOT technology and applications have developed rapidly. The Internet of Things collects various real-time monitoring information through some collectors. Connecting objects and objects or objects and people through the network realizes intelligent perception or identification and management of objects and processes, which uses big data technology. Real-time processing of massive data generated by IOT devices can increase data value density and quickly respond to business events, which is of great value and significance for helping enterprises find problems and take timely governance measures.

\section{Related Work}

With the continuous development of the Internet of Things, the number of small- and medium-sized enterprises is increasing, and the governance problems they face are becoming increasingly prominent. In response to this problem, many scholars have conducted in-depth research and proposed some related governance schemes. Hanna et al. analyze a business model of a decentralized microgrid model (This mode refers to the design of the network topology, including the electrical wiring network structure inside the microgrid, the power supply system (DC/AC power supply and threephase/single-phase power supply), and the corresponding load and the node location of the microgrid where the distributed power source is located); they provide tools based on the Dis- tributed Energy Customer Adoption Model (DER-CAM, DER-CAM is based on the calculation of "determining heat by electricity" and based on the hybrid linear model; it is changed to "determining electricity by heat" which is more in line with the current distributed energy planning and operation) modeling framework, a tool that determines the costminimum capacity and operation of distributed energy sources in microgrids. Hanna et al. quantify the economics of electricity and thermal energy self-sufficiency and explicitly address technical and policy variables [1]. Hendriani et al. study the impact of knowledge management, entrepreneurial motivation, and sociocultural performance on female microenterprise performance. Hendriani et al.'s research uses a survey method to train and survey 121 female microentrepreneurs who are located in different regions. The results of the survey showed that after the training, the business performance of these entrepreneurs has improved, sales have also increased, and the number of consumers of the product has also increased. However, the business improvement of this method is not very large, and more efficient training is needed [2]. Based on a job demand-resource model, Kim et al. investigate how immigrant microbusiness owners (MBOs) cope with their unusually demanding occupations and how MBOs' unresolved occupational stress manifests in psychological distress. Kim et al. compared MBOs to employees in terms of the relationship between emotional demands, job resources, and depressive symptoms. Its research survey shows that MBOs are mostly willing to accept in the early stage when dealing with their unusually demanding occupations, and the early MBO work efficiency is also quite high. However, with the passage of time, their mood fluctuations become larger and larger, eventually leading to two outcomes: one is the final emotional outburst, and the other is a high probability of depression [3]. Through interviews with 30 microenterprises, Achtenhagen et al. explore the core business development activities of microenterprises and the challenges they face in doing so. Achtenhagen et al. have identified three core business development activities (i.e., develop customers, maintain customers, and resell) that leverage the enterprise resource base, complemented by three supporting activities that secure and organize enterprise resources. And Achtenhagen et al. concluded that business development activities are closely related to three practices of utilizing, protecting, and organizing resources [4]. Cesena et al. combine a bespoke Transactive Energy (TE) approach to propose a new technoeconomic framework, which incorporates a custom Mixed Integer Linear Programming (MILP) model (The model requires a mathematical program in which all or some of the variables in the problem are integers. It is generally believed that nonlinear integer programming can be divided into linear parts and integer parts, so integer programming is often regarded as a special part of linear programming. In linear programming problems, some optimal solutions may be fractions or decimals, but for some specific problems, the solutions are often required to be integers.) for the operation of MG. The modeling and evaluation of the framework are powered by microgrids (MG), completing the business case for reserve and novel reliability services. The findings of Cesena et al. show that even though the operating 
schedule of equipment in an MG can vary depending on the different technologies and price signals considered, services are largely synergistic [5]. Using sales growth as a dependent variable, Shibia and Barako investigate the impact of investment climate and firm-specific variables on the growth of micro- and small enterprises (MSEs) in Kenya. The survey included investment climate variables-entrepreneurs' responses to business disputes in court, access to formal credit, and ties to utilities. They investigate perceptions of fairness and affordability in terms of crime occurrence and whether firm-specific resources affect MSE growth. Findings from Shibia and Barako show that active entrepreneurs endorse the fairness and affordability of courts. The survey found that access to formal credit, strong ties to utilities, lower crime rates, and positive perceptions of entrepreneurial education and experience had a positive impact on MSE growth [6]. Although the research has a certain effect on the governance of microenterprises, many of the effects are very obvious or even very weak. At present, these studies have little effect on the significant improvement of the governance of microenterprises, and some of them are only for some specific microenterprises, and their applicability is not high.

\section{Microenterprise Governance Methods under the Internet of Things Big Data}

\subsection{The Current State of Microenterprises}

(1) Definition of Microenterprises. The definition of microenterprises is based on the classification standards of the relevant national department system ("Several Opinions of the State Council on Further Promoting the Development of Small- and Medium-Sized Enterprises," etc.), and the classification standards are based on the scale and characteristics of the enterprises. The scale of an enterprise mainly refers to the number of employees and the total assets of the enterprise, and the characteristics of an enterprise mainly refer to the scope of operation of the enterprise, such as agriculture, handicrafts, and construction.

(2) Characteristics of Microenterprises. According to the enterprise regulations in Table 1, microenterprises generally have assets, operating income, and relatively few employees. Moreover, due to the limited size of microenterprises, the organizational structure of microenterprises is relatively simple. Generally, there are only bosses and grass-roots employees, and there are few middle management in microenterprises. Small- and medium-sized enterprises have a single profit-making method, few management regulations, and insufficient operating experience of enterprise personnel. In addition, according to the data collation of a large number of relevant materials in this paper, two kinds of graphs of the general development status of microenterprises are obtained, as shown in Figure 1 [7].
It can be seen from the rapid development-defunct curve in Figure 1(a) that this type of microenterprises developed rapidly in the early stage of their business ventures and also declined rapidly in difficult times. After the difficult period, the enterprise also developed rapidly. However, in the process of development, this kind of enterprise suddenly collapsed quickly. As can be seen from the slow developmentstable curve in Figure 1(b), the development of this type of enterprise is relatively slow in each period, but its volatility is relatively small and the overall enterprise is on the rise and ultimately remains in a basically stable trend. The main reason for this is that the governance of enterprises is different. The former focuses on the development and ignores corporate governance, while the latter achieves stable development under strict governance [8].

(3) Difficulties Faced by Microenterprises. As shown in Figure 2, there are about 11.7 million microenterprises in China, accounting for more than $75 \%$ of the total number of enterprises. Small- and medium-sized enterprises occupy about $80 \%$ of the domestic labor force, which greatly promotes the growth of the domestic economy. Although smalland medium-sized enterprises have achieved such impressive performance and made great contributions to the development of the national economy, there are also many worrying problems in the process of development. It can be said that it is a combination of difficulties, hot spots, and bright spots [9].

At present, the problems faced by small- and mediumsized enterprises are mainly in four aspects: capital, manpower, management, and market competition, for example, lack of funds, lack of manpower, backward management, and high market competition pressure. Since most of the small- and medium-sized enterprises in China are managed by families, the governance of enterprises is largely conservative and closed, and the control rights of enterprises are relatively concentrated. Figure 3 shows the three-ring model of a family business, which uses the traditional family system and the trust relationship between its members to establish a common interest goal. Their products are highly specialized, their management structure is simple, and their production and operation decisions are quick. Because their enterprises are run by the owners themselves, the ownership and management rights are highly unified, which greatly reduces the agency costs of the enterprises, and the management incentive problem is not prominent. However, over a long period of time, there will inevitably be many disadvantages that restrict the development of enterprises. For example, family financing will inevitably make it difficult for the enterprise to expand and meet the development needs of the enterprise. The power of family members in a family business is too concentrated, which makes it difficult for other excellent management talents to enter higher management levels and restricts the development of the enterprise. The lack of strict laws and regulations in family business governance will inevitably lead to randomness and unfairness of governance, which will increase corporate risks [10]. 
TABLE 1: Regulations for domestic small enterprises.

\begin{tabular}{|c|c|c|c|c|}
\hline Firm name & Name of index & Unit of measurement & Small enterprise & Microenterprise \\
\hline Agriculture, forestry, animal husbandry, and fishery & Operating receipt $(y)$ & Ten thousand yuan & $50 \leq y<500$ & $Y<50$ \\
\hline \multirow{2}{*}{ Industry } & Employee $(x)$ & Person & $20 \leq x<300$ & $X<20$ \\
\hline & Operating receipt $(y)$ & Ten thousand yuan & $300 \leq y<2000$ & $Y<300$ \\
\hline \multirow{2}{*}{ Construction business } & Operating receipt $(y)$ & Ten thousand yuan & $300 \leq y<6000$ & $y<300$ \\
\hline & General assets $(z)$ & Ten thousand yuan & $300 \leq z<5000$ & $z<300$ \\
\hline \multirow{2}{*}{ Etail trading } & Employee $(x)$ & Person & $10 \leq x<50$ & $x<10$ \\
\hline & Operating receipt $(y)$ & Ten thousand yuan & $100 \leq y<500$ & $y<100$ \\
\hline \multirow{2}{*}{ Catering industry } & Employee $(x)$ & Person & $10 \leq x<100$ & $x<10$ \\
\hline & Operating receipt $(y)$ & Ten thousand yuan & $100 \leq y<2000$ & $y<100$ \\
\hline
\end{tabular}

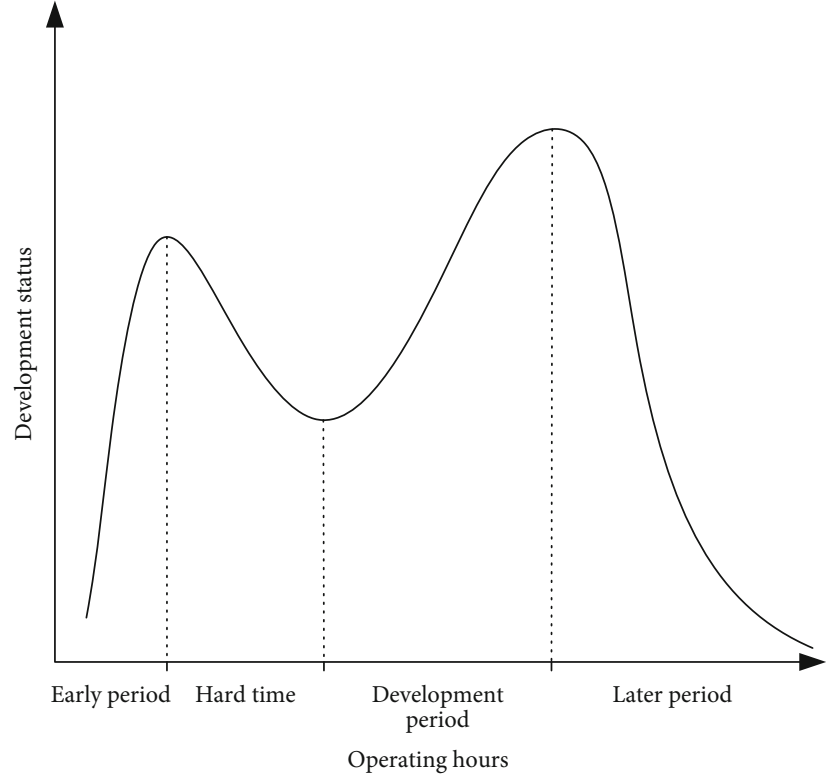

(a) Rapid development-collapsed type

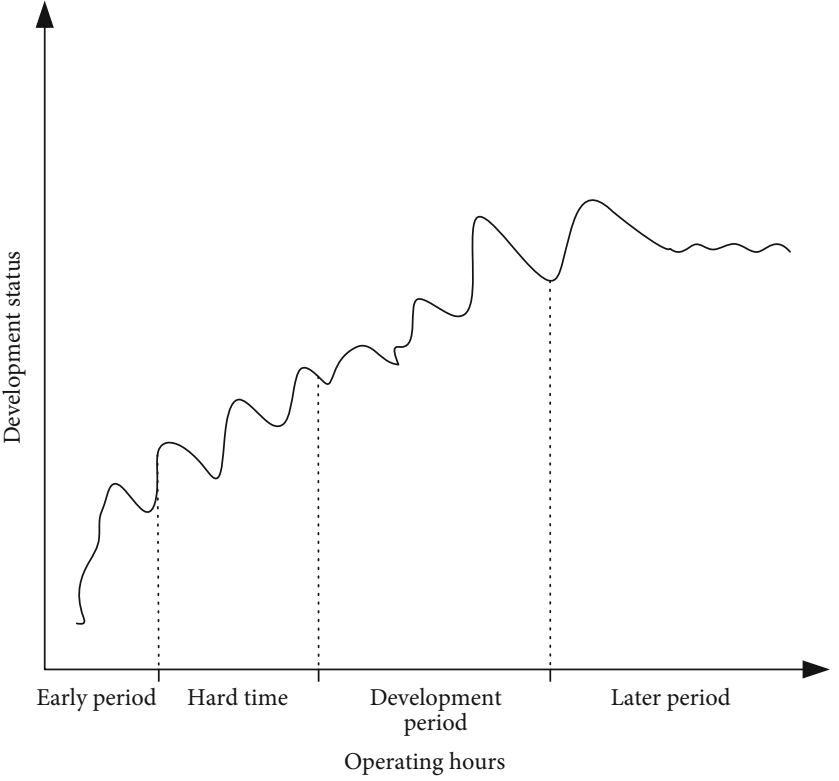

(b) Slow development-stable type

FIGURE 1: Development curve of microenterprises.

\subsection{IOT Big Data}

(1) Concept. The Internet of Things (IOT for short), which is the "Internet of Everything Connected," is a huge network formed by combining various information sensing devices with the Internet. Its goal is to realize the interconnection of people, machines, and things at any time and place. With the continuous advancement of artificial intelligence technology and communication technology, the development of the Internet of Things has entered a new stage, and hundreds of millions of Internet of Things terminals have been installed. These IOT terminals are deployed in production and life, generating massive data, which are collectively referred to as IOT big data. This data is sent to servers for real-time streaming and offline batch processing to guide decision-making. Figure 4 exemplifies the sources of most IOT big data [11].
(2) Characteristics of Big Data. The Internet of Things serves the society with "things" or the physical world as the data source and is a data-centric network. It covers a wide range, including satellite positioning, video surveillance, driving recorders, intelligent identification, education and medical care, entertainment and leisure, and many other fields. Its data volume is large, and the current big data includes billions of records and petabyte-level data volume. Its update speed is fast, and the IOT big data flows at a speed of hundreds of thousands of pieces of data per second [12].

(3) Challenges Faced by IOT Big Data. The design of the Internet of Things application system must take data storage and management as the core and database 


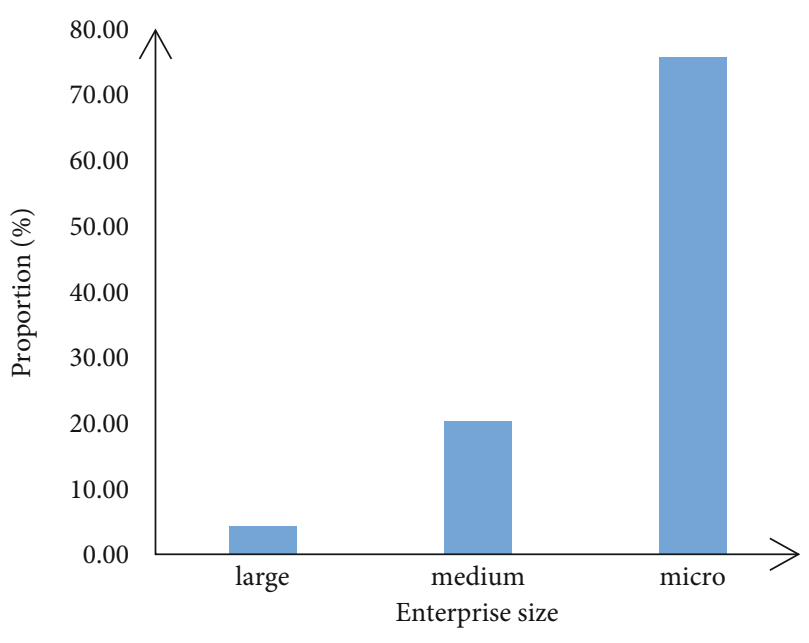

(a) The proportion of enterprises

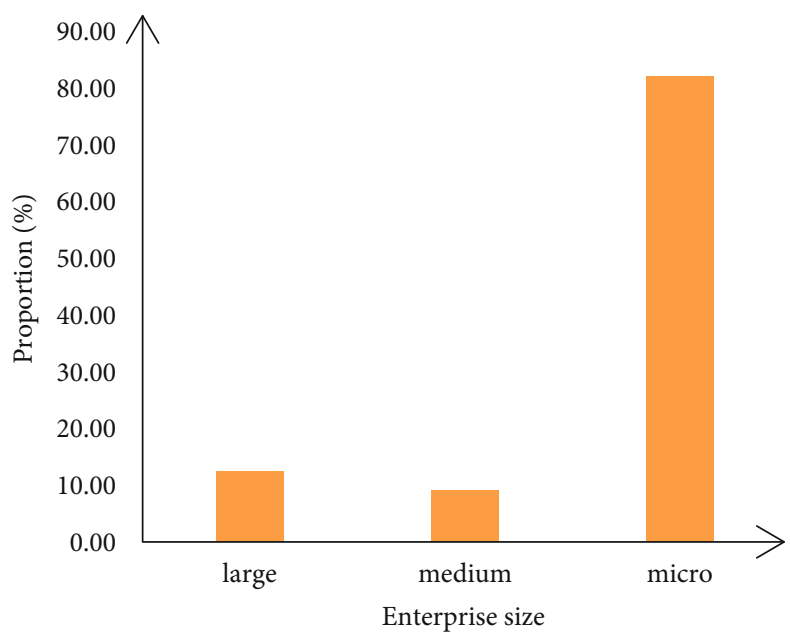

(b) The proportion of labor force

FIgURE 2: The proportion of domestic enterprises by scale.

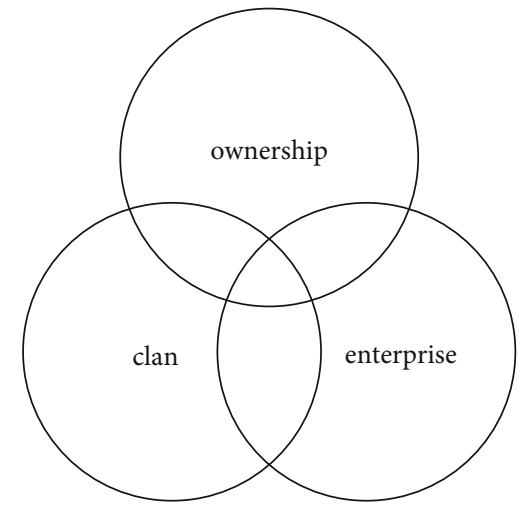

FIgURE 3: The three-ring model of a family business.

technology as the core and provide users with an effective data storage and management system from conceptual logic and software and hardware technology. The system needs to consider massive data storage, highperformance data analysis, and retrieval based on data mining. However, until now, data storage and management techniques have not been effectively applied to IOT. There are many problems to be solved in data storage, query, and analysis based on decision analysis. This brings new challenges and new tasks to database management and also brings new opportunities for the development of database management. In addition, the large amount of data in the Internet of Things has an impact on traditional data storage and management techniques. For example, in image capture and object recognition for the Internet of Things, the most widely used Hadoop distributed system can only write $10 \mathrm{~K}$ pictures the second time around. In terms of data retrieval, IOT data retrieval services can only be provided in the form of offline batch index structures. In data processing, it can only provide a target detection speed of dozens of frames per second. In task management and control, it does not support energy-saving task scheduling [13].

\subsection{Microenterprise Governance Theory}

(1) Life Cycle Theory Governance Scheme. The theory divides the whole process from birth to decline of an enterprise into several different stages and studies its characteristics and existing problems according to the specific conditions of enterprises in different stages. The researchers said that the division of each stage is different, but the classification standard is generally determined according to the development starting point, maturity, degradation, and extinction laws of the life cycle [14].

(2) Theoretical Governance Scheme of Core Competitiveness. Core competitiveness solves the problem of sustainable competitive advantage of enterprises, and it is the source of sustainable competitive advantage of enterprises. As shown in Figure 5, at every stage of enterprise development, it should have core competitiveness, and if an enterprise has core competitiveness, the enterprise will be a step closer to success. Small- and medium-sized enterprises that grow up in the fierce market competition only become bigger when they have core competitiveness, rather than cultivating core competitiveness after they become big [15].

(3) Principal-Agent Theory Governance Scheme. Due to the fragility of family businesses, these small businesses need to find ways to resolve or balance the conflicts and losses brought about by these deficiencies. Therefore, family businesses with a limited capacity will seek a special kind of manager, namely, the principal-agent system. However, this governance scheme is limited by the strength and effort of the agent. Figure 6 shows the relationship between the agent and the output value of the enterprise [16]. 


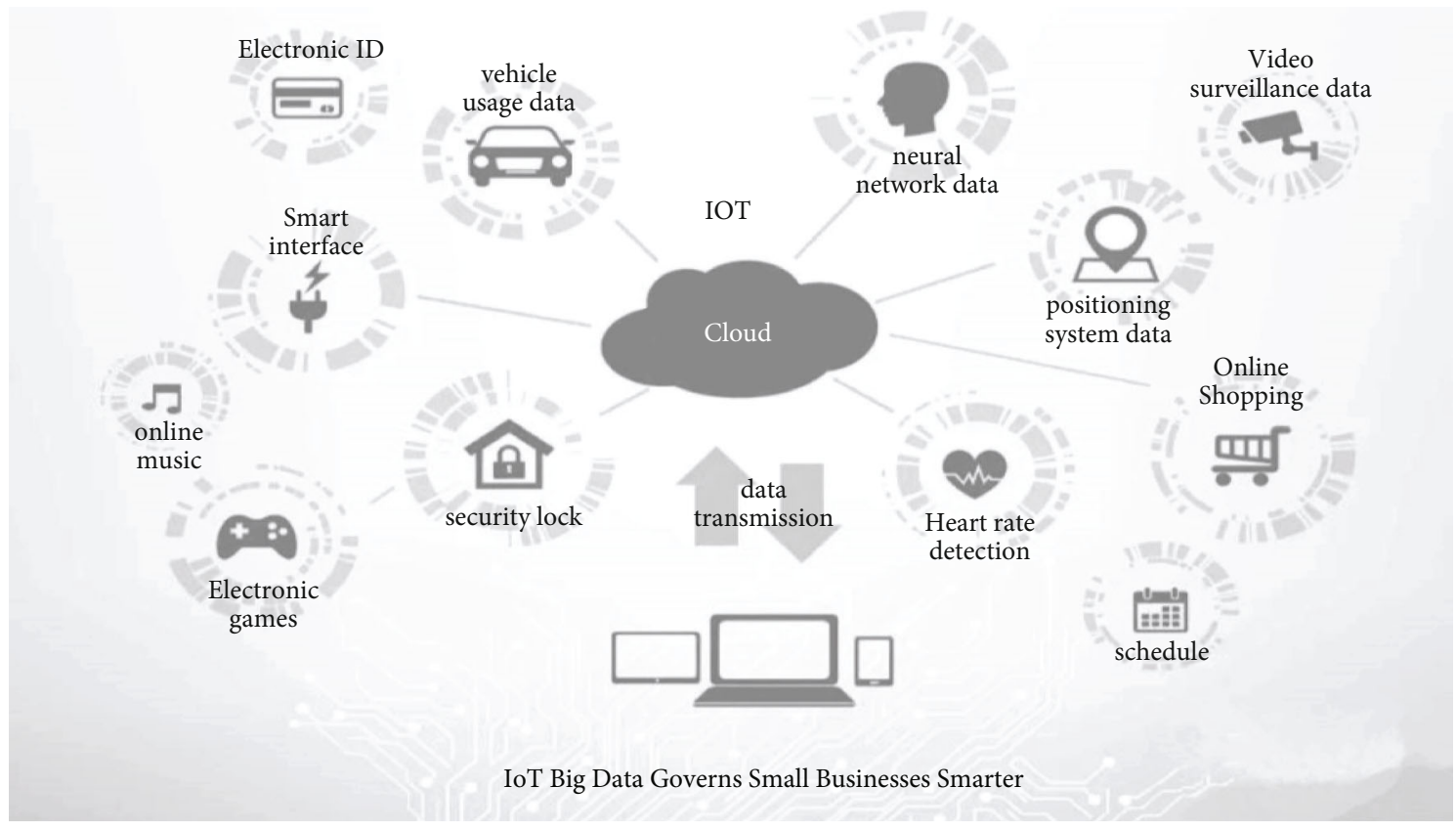

Figure 4: IOT big data.

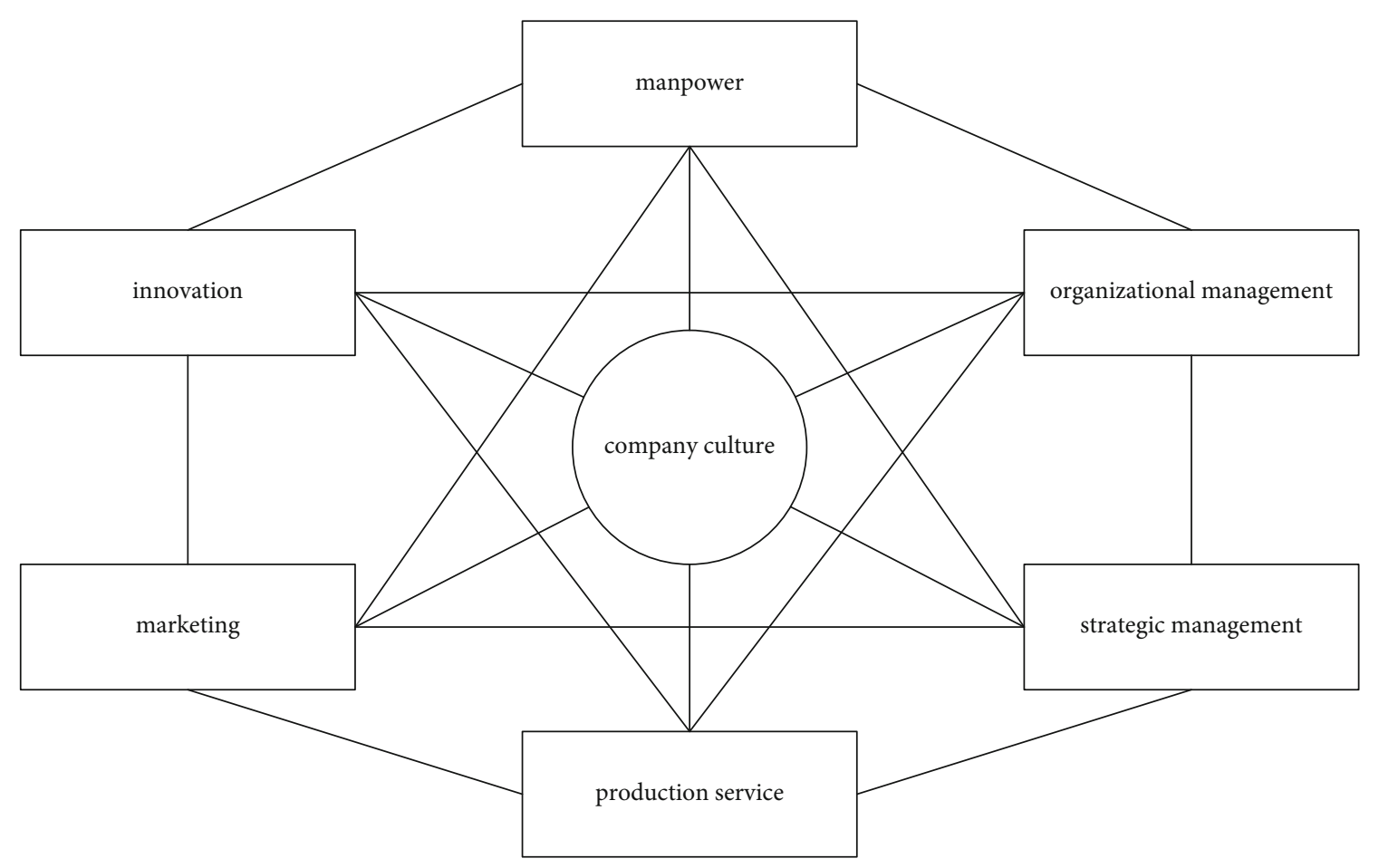

Figure 5: Core competitive theory relationship diagram. 


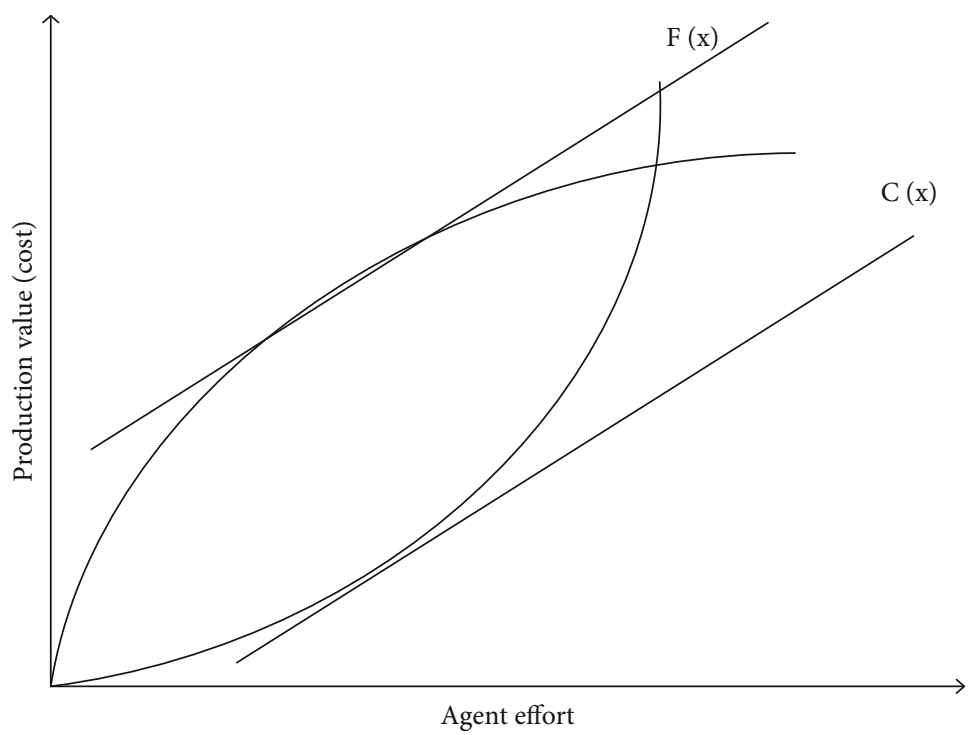

FIGURE 6: Principal agent and output value relationship.

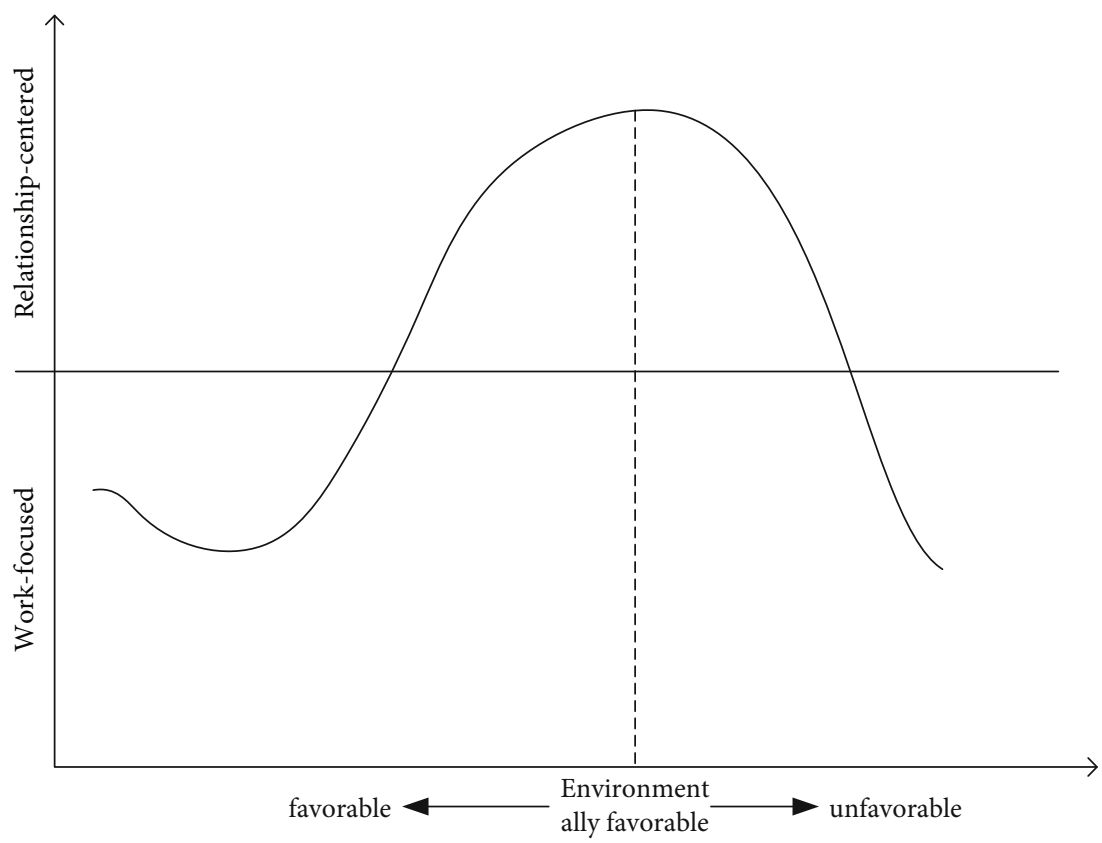

FIgURE 7: Contingency management curve.

(4) Governance Scheme of Contingency Management Theory. Figure 7 is a graph of the theory. The contingency management theory believes that enterprises must change according to changes in internal and external environments, and the choice of corporate governance modes must also be changed. Every enterprise must choose according to its own characteristics and external environment, and there is no fixed optimal model to choose from. Everything should have a contingency selection process based on one or more of the most important factors affecting the business [17].
Each of these four theories has its own characteristics, and it needs to be properly applied according to the different characteristics and structure of the enterprise to achieve the effect expected by the theory.

\subsection{Effective Measures Taken by Microenterprise Governance}

(1) Effective Use of Enterprise Resources. There are many kinds of enterprise resources, such as funds, machinery and equipment, talents, and social relations. How to make the most use of these resources in order to create more profits is a problem placed in front of 
every enterprise organization. In order to make full use of various resources and maximize the release of human, material, and financial resources, it is necessary to integrate and manage various information, such as an information management evaluation method as shown in Table 2 [18].

(2) Strengthening the Quality of Enterprise Employees. The development of enterprises is inseparable from the role of people, and the relationship between enterprises and people is closely linked. The competition among enterprises is intensifying day by day, and enterprises continue to carry out technological innovation and management innovation. And the core resource on which the technological innovation and management innovation of the enterprise rely is the carrier of knowledge and knowledge-enterprise employees. Enterprises can better assign positions to employees by establishing an employee quality evaluation system, such as an employee quality evaluation table shown in Table 3.

(3) Balanced Distribution of Benefits. There are many tasks to be completed in all aspects of the work of the enterprise, and there are many small organizations and departments. If they want to complete their various tasks, conflicts of interests and resources will inevitably occur. If an enterprise wants to develop, it must face up to these conflicts to balance the relationship among all aspects, so that the enterprise can reach an agreement on resource allocation and benefit-sharing, that is, can maintain a balance between organizations and departments. To maintain this balance, enterprises should try to find the relationship between each other and evaluate them with numerical values, as shown in Table 4 which is the evaluation table of ongoing work operation and business resource assurance [19].

(4) Strengthening Communication between Various Departments. The particularity of corporate governance itself is destined to need to coordinate and communicate with all parties. Communication can be supported by stakeholders and other external conditions and reduce the probability of encountering resistance in the process of corporate governance, so that the implementation of corporate governance can proceed as far as possible toward the plan. When the enterprise goal is deviated and faces the danger of losing control, communication can help the project manager to rely on multiple forces to correct the deviation and take measures to control the project goal [20].
(5) Appropriate Revision Plans and Goals. According to the actual progress of corporate governance, with the consent of stakeholders, the original plans and goals can be appropriately revised, and new plans and goals can be formulated.

(6) Taking Certain Measures and Management Methods. When choosing solutions according to the actual situation, it must be noted that the entire governance activities must conform to the overall goals of the enterprise; the measures must be timely and effective, acceptable to stakeholders; and the management methods must be scientific and reasonable. These measures and management methods must be coordinated with other corporate economic behaviors and activities [21].

\section{Microenterprise Governance Scheme for IOT Big Data}

\subsection{IOT Big Data Management Optimization Algorithm}

(1) Collaborative Algorithm. If the coefficient formula is used for strain selection in an unstable subsystem with $n$ parameters, then the $n$-dimensional vector can be expressed as

$$
\vec{q}=\left\{q_{1}, q_{2}, \cdots, q_{j}, q_{n}\right\}
$$

Its movement form is

$$
q=k_{j}(\vec{q})+\xi_{j}(t)
$$

where $k_{j}$ is the functional function of the parameters and $\xi_{j}$ is the time disturbance.

If the disturbance is ignored, it can be expressed as

$$
q=\sum_{k=1}^{n} a_{j k} q_{k}+f_{t}(\vec{q})
$$

where $f_{t}$ is one of the functions of this vector.

The fixed point of the system can be regarded as stable, so appropriate coordinates can be selected for updating, namely,

$$
q_{1}=r_{1} q_{1}+g_{1}\left(q_{1}, q_{2}, \cdots, q_{j}, \cdots, q_{n}\right) .
$$

The same can be extended to

$$
q_{n}=r_{n} q_{n}+g_{n}\left(q_{1}, q_{2}, \cdots, q_{j}, \cdots, q_{n}\right),
$$

where $g_{n}$ is another function of this vector. 
TABLE 2: Management information evaluation form.

\begin{tabular}{lccc}
\hline Management information & Standard value & Score & Evaluation result \\
\hline Decision-making informatization support degree & $100 \%$ & $95 \%$ & Excellent \\
Enterprise database construction level & $100 \%$ & $90 \%$ & Excellent \\
Informatization of financial management & $100 \%$ & $60 \%$ & Level 2 \\
Human resource informatization & $100 \%$ & $20 \%$ & Level 4 \\
\hline
\end{tabular}

TABle 3: Personnel quality assessment form.

\begin{tabular}{lccc}
\hline The quality of personnel & Standard value & Score & Evaluation result \\
\hline Communication and collaboration & 100 & 10 & Level V \\
Employee education level & 100 & 90 & $90 \%$ \\
Employee training ratio & 100 & 50 & $50 \%$ \\
Leadership awareness & 100 & 80 & Value and participate \\
\hline
\end{tabular}

TABLE 4: Safety operation and business assurance evaluation form.

\begin{tabular}{lccc}
\hline Safe operation and business assurance & Standard value & Score & Evaluation result \\
\hline Equipment automatic monitoring index & 10 & 8 & Excellent \\
Communication service guarantee index & 10 & 6 & $60 \%$ \\
Safe operation index & 10 & 1 & Unqualified \\
Information security index & 10 & 4 & From level 7 I \\
\hline
\end{tabular}

For complex and multidimensional systems, the main parameter $u$ is included, and the variable is

$$
u=-\gamma_{1} u+g_{1}\left(u, q_{2}, \cdots, A_{D}, \cdots, q_{j}, \cdots, q_{n}\right)
$$

Among it,

$$
A_{D}=-r_{a} A_{D}+g_{a}\left(u, q_{2}, \cdots, A_{D}, \cdots, q_{j}, \cdots, q_{n}\right) .
$$

Getting

$$
q_{n}=-r_{n} q_{n}+g_{n}\left(u, q_{2}, \cdots, A_{D}, \cdots, q_{j}, \cdots, q_{n}\right)
$$

Making

$$
q_{2}=h_{2}(u), A_{D}=h_{a}(u), q_{n}=h_{n}(u) .
$$

Finally, the parametric formula can be obtained:

$$
u=-\gamma_{1} u+g_{1}\left(u, q_{2}, \cdots, A_{D}, \cdots, q_{j}, \cdots, q_{n}\right)=-\gamma_{1} u+G(u)
$$

(2) Pareto Optimal Algorithm. The optimal condition (1) is that the marginal replacement coefficient of products in microenterprises is consistent with any consumer, which can be expressed as

$$
\operatorname{RCS}_{X Y}^{A}=\operatorname{RCS}_{X Y}^{B}
$$

In the formula, $A$ and $B$ represent random consumers and $X$ and $Y$ represent random products.

The optimal condition (2) is that the marginal technology replacement coefficient of products in microenterprises is consistent with any producer, namely,

$$
\operatorname{RTS}_{L K}^{C}=\operatorname{RTS}_{L K}^{D}
$$

In the formula, $C$ and $D$ represent random producers and $L$ and $K$ represent random products.

When the optimal conditions (1) and (2) are satisfied, the edge transformation effect of the product in the microenterprise is consistent with the edge replacement effect, namely,

$$
R C S_{X Y}=R P T_{X Y}
$$

In a perfectly competitive economy, the optimal state of exchange is the following: the marginal substitution coefficient of any two commodities is equal to the price ratio of these two commodities, namely,

$$
\operatorname{RCS}_{X Y}^{A}=\operatorname{RCS}_{X Y}^{B}=\frac{P_{X}}{P_{Y}}
$$

And in a perfectly competitive economy, the optimal state of production is the following: the marginal technology replacement coefficient of any two factors is equal to the 


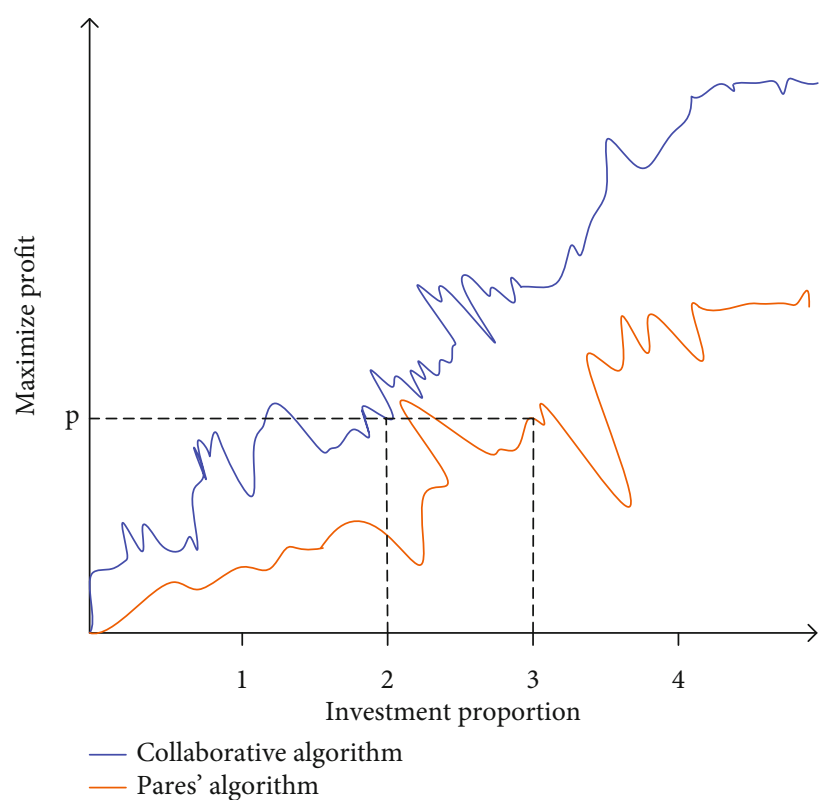

(a) The relationship between investment proportion and profit maximization

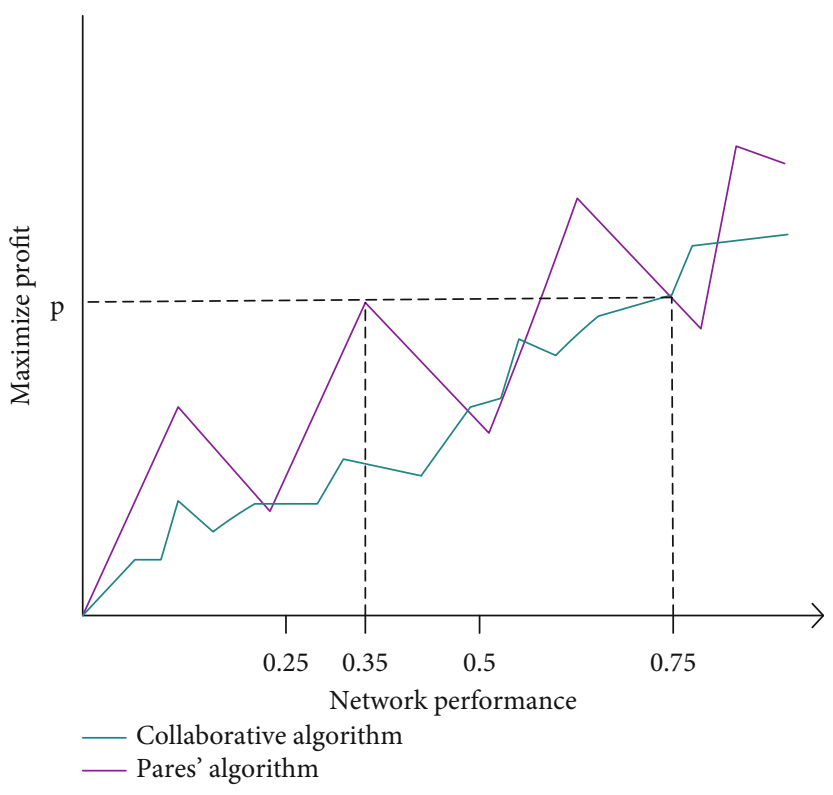

(b) The relationship between network performance and profit maximization

FIGURE 8: Implementation evaluation comparison of the two algorithms.

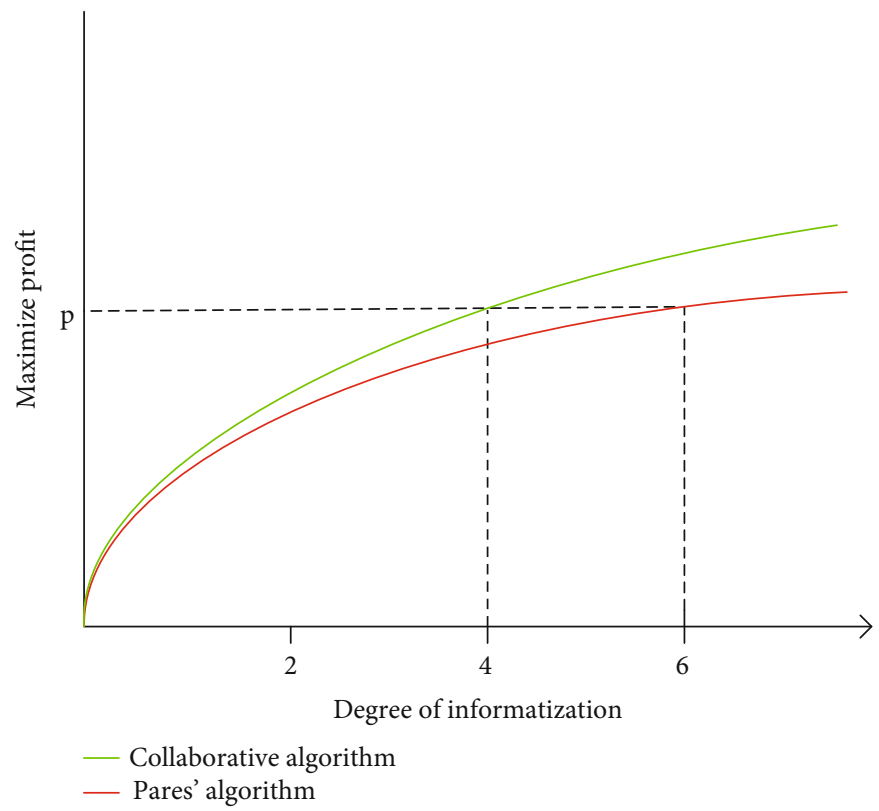

FIGURE 9: The relationship between the degree of informatization and profit maximization of the two optimization algorithms.

price ratio of these two commodities, namely,

$$
R T S_{L K}^{C}=R T S_{L K}^{D}=\frac{P_{L}}{P_{K}} .
$$

In a perfectly competitive economy, the optimal state of production and exchange is

$$
R P T_{X Y}=\left|\frac{\Delta Y}{\Delta X}\right| .
$$

In the formula, $\Delta X$ represents the edge conversion cost of $Y$ and $\Delta Y$ represents the edge production cost of $X$.

Then, the marginal conversion coefficient of $X$ and $Y$ products can be regarded as the comparison of the two costs, namely,

$$
\left|\frac{\Delta Y}{\Delta X}\right|=\frac{M C_{X}}{M C_{Y}} .
$$

In perfect competition, the condition for maximizing the producer's profit is that the price of the product is equal to 


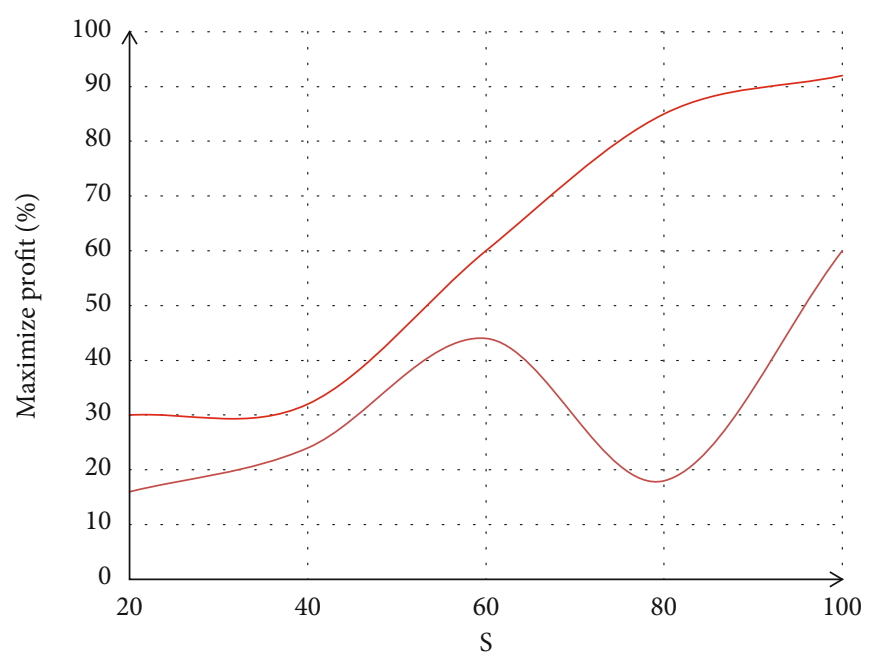

(a) Comparison of scheme A and traditional scheme

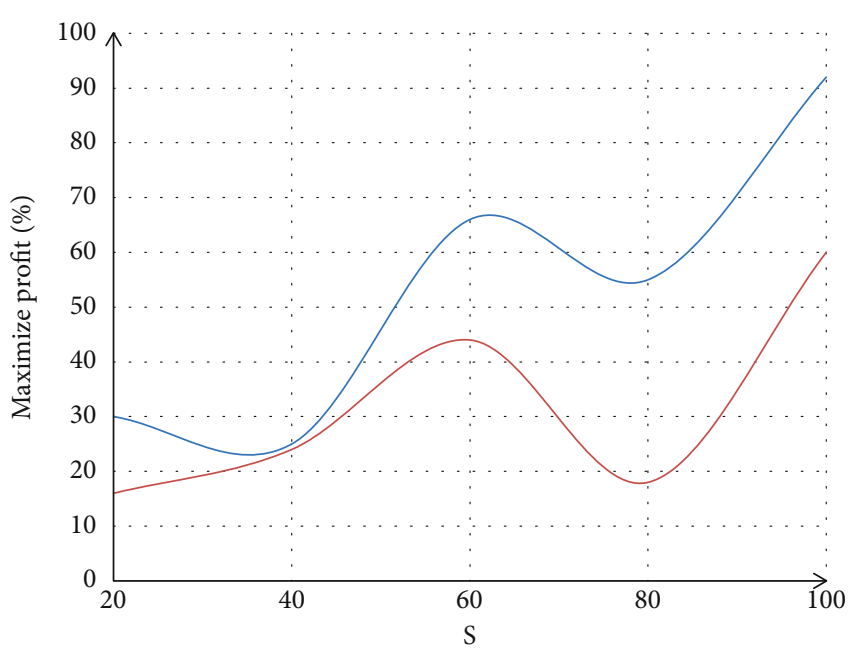

(b) Comparison between scheme B and traditional scheme

Figure 10: Comparison of schemes A and B with traditional schemes.

its marginal conversion and production costs, so getting

$$
\begin{aligned}
& M C_{X}=P_{X}, \\
& M C_{Y}=P_{Y} .
\end{aligned}
$$

It is finally expressed as

$$
\frac{M C_{X}}{M C_{Y}}=\frac{P_{X}}{P_{Y}} .
$$

Both of these algorithms can calculate the maximum profit of the enterprise, but the collaborative algorithm is relatively conservative and the algorithm is more rigorous. The Pareto algorithm, on the other hand, is more ideal, which may lead to relatively high volatility in the results.

\subsection{Evaluation and Comparison of Microenterprise Governance}

(1) Evaluation and Comparison of the Implementation Level of Microenterprise Governance. Figure 8(a) is a graph of the investment proportion and maximized profit implemented under the two optimization algorithms. It can be seen from the figure that the investment proportion of the Pareto optimization and upgrading plan is compared with that of the synergistic plan. Under the same maximum profit value, the investment proportion of the synergistic plan is about $2 / 3$ of that of Pareto. And the synergistic scheme is relatively stable in an upward trend until stable, while the Pareto scheme has relatively large up and down fluctuations. The test of network performance mainly revolves around response time, required number of concurrent users, cost, standard and peak value, degradation caused by stress, and reliability. The network performance test is mainly through four methods: benchmark performance test, load test, stress test, and reliability test.
Figure $8(\mathrm{~b})$ is a graph of the size and performance of the communication network implemented under the two optimization algorithms and maximized profits. Under the same maximum profit value, the network performance requirement of the Pareto scheme is about $7 / 15$ of that of the synergistic scheme, but the Pareto fluctuation peak and fluctuation range are obviously larger, and the advantages and disadvantages are prominent [22].

(2) The Evaluation and Comparison of the Information Management Level of Microenterprise Governance. It is of great significance to deepen the application degree of human resource informatization, financial management informatization, enterprise data informatization, and decision-making informatization. According to the needs of the user training module in the support and training plan in the governance optimization plan, actively carry out E-HR system business diffusion training to ensure that human resource managers are proficient in the system, actively promote system data rectification work, and solve the problems of errors during data migration and maintenance to improve data quality. Figure 9 is a graph of the investment proportion and maximized profit implemented under the two optimization algorithms. It can be seen from Figure 9 that under the same maximum profit value, the informationization of the Pales scheme is about $2 / 3$ of that of the collaborative scheme.

Finally, combining the characteristics of the two algorithms, this paper conducts a selective test of microenterprise governance in different aspects and obtains two sets of optimal solutions A and B. Scheme A uses the collaborative algorithm in terms of network performance, while $B$ uses the Pareto algorithm. In the test, the comprehensive 
management level of the two groups of schemes is recorded as $\mathrm{S}$, and the two schemes are compared with the traditional scheme, as shown in Figure 10.

In this paper, the performance evaluation of microenterprise governance is based on the principles of "simplicity, precision, and efficiency." It changes the traditional evaluation method of relying on a single superior management in the past and conducts evaluation through daily information verification, ERP information system data extraction, and other methods to improve work efficiency and quality and ensure the accuracy of evaluation results. After evaluation, it is concluded that the final profit maximization degree of $\mathrm{A}$ and $\mathrm{B}$ schemes can reach $92 \%$, which is higher than 85 points, so they belong to the excellent governance stage. The two differences are that the governance effect of the A scheme is relatively stable, the B scheme fluctuates greatly but the overall increase, and when the governance level is in the middle, the Figure B scheme has a higher degree of profit maximization. Comparing the two schemes with the traditional scheme, it can be seen that the maximum profit of the enterprise has been greatly improved after the implementation of governance, by about $30 \%$.

\section{Discussion}

There are two main deficiencies in the theoretical framework of this paper: First, the governance structure is positioned at the top of the enterprise and driven by the specific business needs of the enterprise to guide the entire IT process of the enterprise. Therefore, it only stipulates the goal and content of governance but does not explain how to implement the business process under the guidance of the governance strategy formulated by the top management of the enterprise. The second is that the content of the evaluation test is not detailed enough, and the implementation plan of the key process is not explained, and the process needs to be redesigned according to the practice later. The utility theory in the process of enterprise capability evaluation is a mathematical theory established on the basis of the evaluation subject's personal values. It contains many assumptions and cannot form an index evaluation system that is relatively practical for other companies, which makes the data in the paper unconvincing [23].

This paper makes a more in-depth analysis of IOT big data governance but only builds a static microenterprise governance framework. It does not include different governance subjects and different types of paths through mathematical modeling to form a dynamic and brand-new theory of research governance, so it needs to be further improved in the future.

\section{Conclusions}

In the research of the microenterprise governance scheme, this paper firstly explains the background meaning of the microenterprise in the abstract part, then explains the purpose of this research and the theoretical algorithm used, and gives a detailed description of the evaluation test results. Then, the article explains the big data background of the
Internet of Things, the status quo of microenterprises, and the value of this research in the reference part. In the related work, this paper cites many scholars' related researches on microenterprise governance and analyzes their research results and the shortcomings of their research. In the part of theoretical research, this paper firstly introduces the status quo of microenterprises, including the definition range of microenterprises, the characteristics of microenterprises, and the difficulties faced by microenterprises. Then, this paper introduces the concept, characteristics, and challenges of IOT big data and explains it with the help of charts. Secondly, the article introduces several important theories of microenterprise governance. Finally, in the design of the optimization and upgrading scheme, the article mentioned the use of the collaborative algorithm and Pareto algorithm to optimize and upgrade. After many evaluation tests, two groups of optimal solutions were finally obtained, and the two groups of solutions were evaluated and tested, and compared with the traditional solutions, the advantages of the two sets of solutions proposed in this paper were obtained. Finally, two groups of optimal schemes are obtained, and the two groups of schemes are evaluated and tested, and compared with the traditional schemes, the advantages of the two groups of schemes proposed in this paper are obtained. That is, the maximum profit of both schemes can reach $92 \%$, which is about $30 \%$ higher than the traditional draft.

\section{Data Availability}

The experimental data used to support the findings of this study are available from the corresponding author upon request.

\section{Conflicts of Interest}

The authors declare that there is no conflict of interest with any financial organizations regarding the material reported in this manuscript.

\section{Acknowledgments}

This work was supported by the Fundamental Research Funds for the Central Universities (Nos. CXJJ-2019-342 and CXJJ2019-325).

\section{References}

[1] R. Hanna, M. Ghonima, J. Kleissl, G. Tynan, and D. G. Victor, "Evaluating business models for microgrids: interactions of technology and policy," Energy Policy, vol. 103, pp. 47-61, 2017.

[2] S. Hendriani, Y. Efni, and E. Tiyasiningsih, "The effect of knowledge, entrepreneurship motives and the society's culture in increasing the women micro business performance in Riau province," International Journal of Law and Management, vol. 61, no. 5/6, pp. 563-574, 2019.

[3] I. H. Kim, S. Noh, C. C. Choi, and K. McKenzie, "Microbusinesses and occupational stress: emotional demands, job resources, and depression among Korean immigrant 
microbusiness owners in Toronto, Canada," Journal of Preventive Medicine and Public Health, vol. 52, no. 5, pp. 299-307, 2019.

[4] L. Achtenhagen, S. Ekberg, and A. Melander, "Fostering growth through business development: core activities and challenges for micro-firm entrepreneurs," Journal of Management \& Organization, vol. 23, no. 2, pp. 167-185, 2017.

[5] E. A. Cesena, N. Good, A. L. Syrri, and P. Mancarella, "Techno-economic and business case assessment of multienergy microgrids with co-optimization of energy, reserve and reliability services," Applied Energy, vol. 210, pp. 896913, 2018.

[6] A. G. Shibia and D. G. Barako, "Determinants of micro and small enterprises growth in Kenya," Journal of Small Business and Enterprise Development, vol. 24, no. 1, pp. 105-118, 2017.

[7] M. Marjani, F. Nasaruddin, A. Gani et al., "Big IoT data analytics: architecture, opportunities, and open research challenges," IEEE Access, vol. 5, no. 99, pp. 5247-5261, 2017.

[8] J. Hopkins and P. Hawking, "Big data analytics and IoT in logistics: a case study," The International Journal of Logistics Management, vol. 29, no. 2, pp. 575-591, 2018.

[9] C. X. Mavromoustakis, G. Mastorakis, and C. Dobre, The Art of Advanced Healthcare Applications in Big Data and IoT Systems, Springer International Publishing, 2017.

[10] M. A. Ahad and R. Biswas, "Request-based, secured and energy-efficient (RBSEE) architecture for handling IoT big data," Journal of Information Science, vol. 45, no. 2, pp. 227238, 2019.

[11] A. R. Al-Ali, I. A. Zualkernan, M. Rashid, R. Gupta, and M. AliKarar, "A smart home energy management system using IoT and big data analytics approach," IEEE Transactions on Consumer Electronics, vol. 63, no. 4, pp. 426-434, 2017.

[12] D. Zhu, "IOT and big data based cooperative logistical delivery scheduling method and cloud robot system," Future Generation Computer Systems, vol. 86, pp. 709-715, 2018.

[13] M. H. U. Rehman, E. Ahmed, I. Yaqoob, I. A. T. Hashem, M. Imran, and S. Ahmad, "Big data analytics in industrial IoT using a concentric computing model," IEEE Communications Magazine, vol. 56, no. 2, pp. 37-43, 2018.

[14] S. K. Sood, R. Sandhu, K. Singla, and V. Chang, "IoT, big data and HPC based smart flood management framework," Sustainable Computing: Informatics and Systems, vol. 20, pp. 102-117, 2018.

[15] Q. Zhang, L. T. Yang, Z. Chen, P. Li, and F. Bu, "An adaptive dropout deep computation model for industrial IoT big data learning with crowdsourcing to cloud computing," IEEE Transactions on Industrial Informatics, vol. 15, no. 4, pp. 2330-2337, 2019.

[16] A. Yassine, S. Singh, M. S. Hossain, and G. Muhammad, "IoT big data analytics for smart homes with fog and cloud computing," Future Generation Computer Systems, vol. 91, pp. 563$573,2019$.

[17] J. Hayden, "Can you handle the IoT big data onslaught?," Inbound Logistics, vol. 38, no. 5, pp. 52-52, 2018.

[18] F. Neft, K. E. Kappler, and S. Smolnik, "Der Einfluss von IoT-, big-data- und mobile-health-Lösungen auf die Wertschöpfung in Krankenhäusern: gap-analyse und Handlungsempfehlungen," HMD Praxis der Wirtschaftsinformatik, vol. 58, no. 1, pp. 50-63, 2021.

[19] E. Vaahedi, K. Nodehi, D. Heim, F. Rahimi, and A. Ipakchi, "The emerging transactive microgrid controller: illustrating its concept, functionality, and business case," IEEE Power and Energy Magazine, vol. 15, no. 4, pp. 80-87, 2017.

[20] G. K. Mezgebo, T. Ymesel, and G. Tegegne, "Do micro and small business enterprises economically empower women in developing countries? Evidences from Mekelle City, Tigray, Ethiopia," Journal of Organizational Change Management, vol. 30, no. 5, pp. 767-778, 2017.

[21] J. Marcus, F. Kahraman, S. Su, and B. A. Fritzsche, "Capturing intranational cultural variation in international business research: microsocietal differences in collectivism across Turkey," Journal of World Business, vol. 54, no. 6, pp. 101020101020.17, 2019.

[22] M. J. Marcus, "Impacts of spectrum policy on microwave businesses [microbusiness]," IEEE Microwave Magazine, vol. 18, no. 4, pp. 26-30, 2017.

[23] F. Schindler, "The way we work has changed forever [microbusiness]," IEEE Microwave Magazine, vol. 22, no. 1, pp. 9-10, 2021. 